\title{
Nonlinear vibration of oscillation systems using frequency-amplitude formulation
}

\author{
A. Fereidoon ${ }^{\mathrm{a}}$, M. Ghadimi ${ }^{\mathrm{b}}$, A. Bararic,*, H.D. Kaliji ${ }^{\mathrm{d}}$ and G. Domairry ${ }^{\mathrm{b}}$ \\ ${ }^{a}$ Department of Mechanical Engineering, Faculty of Engineering, Semnan University, Semnan, Iran \\ ${ }^{\mathrm{b}}$ Department of Mechanical Engineering, Babol University of Technology, Babol, Iran \\ ${ }^{\mathrm{c}}$ Department of Civil Engineering, Aalborg University, Sohngårdsholmsvej 57, 9000 Aalborg, Aalborg, Denmark \\ ${ }^{\mathrm{d}}$ Department of Mechanical Engineering, Islamic Azad University, Semnan Branch, Semnan, Iran
}

Received 9 October 2010

Revised 3 January 2011

\begin{abstract}
In this paper we study the periodic solutions of free vibration of mechanical systems with third and fifth-order nonlinearity for two examples using He's Frequency-Amplitude Formulation (HFAF).The effectiveness and convenience of the method is illustrated in these examples. It will be shown that the solutions obtained with current method have a fabulous conformity with those achieved from time marching solution. HFAF is easy with powerful concepts and the high accuracy, so it can be found widely applicable in vibrations, especially strong nonlinearity oscillatory problems.
\end{abstract}

Keywords: Nonlinear vibration, He's frequency-amplitude formulation, periodic solution, approximate frequency

\section{Introduction}

Oscillation systems have been widely used in many areas of physics and engineering. These systems have significant importance in engineering particularly in mechanical and structural dynamics. Many practical engineering components consist of vibrating systems that can be modeled using oscillator systems such as elastic beams supported by two springs or mass-on-moving belt or nonlinear pendulum and vibration of a milling machine [1-3].

In recent years, much attention has been devoted to the new developed methods to construct an analytic solution of nonlinear vibration such as Variational Iteration Method [4-7], Homotopy Perturbation Method (HPM) [8,9], Energy Balance Method (EBM) [12-14], Max-Min Method [15,16], Differential Transform Method [17,18], He's FrequencyAmplitude Formulation [19,20], Parameter Expansion Method [21] and etc. Through the continuous development of these methods, many research works have been conducted as follows. Boumediene et al. [22] investigated nonlinear forced vibration of thin elastic rectangular plates subjected to harmonic excitation by asymptotic numerical method. Bayat et al. [23] employed Energy Balance Method to obtain analytical expressions for the non-linear fundamental frequency and deflection of Euler-Bernoulli beams defining the bending behavior of long isotropic beams. Only a first-order approximation leads them to accurate solutions compared to the work presented by Qaisi [24] using harmonic balance approach. Ganji et al. [25] studied static stability of a column by determining the nature of the singular point at $u=0$ of the dynamic equations. Then they considered a two-mass system with three-springs while two equal masses are linked with the linear and nonlinear stiffness namely $k_{1}, k_{2}$ and $k_{3}$, respectively. Eventually, Max-Min approach was utilized to obtain the first and second-order approximate frequencies and periods for these single and two-degrees-of-freedom (SDOF and TDOF) systems [25]. Moreover, Parameter-Expansion Method was employed to develop a closed form solution to the governing equation of a system of nonlinear autonomous

\footnotetext{
*Corresponding author. E-mail: ab@civil.aau.dk.
} 

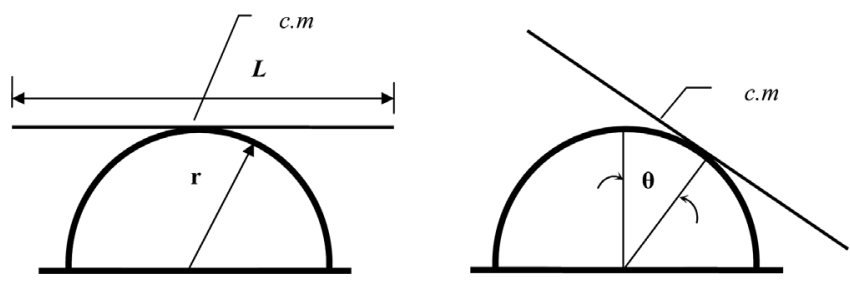

Fig. 1. Rigid rod rocks on a circular surface.

conservative oscillators, describing the large amplitude free vibrations of a restrained uniform beam carrying an intermediate lumped mass along its span [26].

Some other literature which used approximate methods for beam vibration problems are summarized in the following. Jacques et al. [27] analyzed nonlinear vibration of pre-stressed beams. Baghani et al. [28] represented large amplitude vibration and post-buckling analysis of composite beams on elastic foundation and used variational iteration method to solve the cubic nonlinearity equation. An improved He's Energy Balance Method for solving nonlinear oscillatory differential equation using a new trial function was presented by Sfahani et al. [29]. The problem considered represents the governing equations of the non-linear large amplitude free vibrations of a slender cantilever beam with a rotationally flexible root. The fourth-order parabolic differential equations presenting the transverse vibrations of a homogeneous beam are also approximated by Noor et al. [30].

In previous works, He's Frequency-Amplitude Formulation was introduced in simple cases [31-33]. However, through current research authors develop this method for two highly nonlinear vibration problems. In first case the motion equation of the rigid rod rocks on the circular surface is investigated [34]. It is also considered large amplitude vibration of a slender inextensible cantilever beam with intermediate lumped mass with fifth order nonlinearity followed by discussion of the results. Ultimately, the results are verified against time marching and other analytical solutions, and as will be depicted, approximate solutions obtained by current method are in excellent agreement with those obtained by the former one.

\section{Application of He's frequency-amplitude formulation}

In order to demonstrate the application and the accuracy of the frequency-amplitude formulation in oscillator systems, we will consider the following examples:

\subsection{Case 1}

Figure 1 shows the schematic of the rigid rod rocks on a circular surface without slipping [34]. The potential energy of the system can be written as:

$$
U=\operatorname{mgr}(\theta \sin \theta+\cos \theta-1) .
$$

The kinetic energy can be expressed as:

$$
T=\frac{1}{2} m V_{G}^{2}+\frac{1}{2} I_{G} \omega^{2}
$$

Where, $V_{G}, I_{G}$ and $\omega$ are as below:

$$
V_{G}=r \dot{\theta} \dot{\theta}, \quad I_{G}=\frac{1}{12} m l^{2}, \quad \omega=\dot{\theta}
$$

The motion equation of the system by applying Lagrangian [34] can be found as:

$$
\left(\frac{1}{12} l^{2}+r^{2} \theta^{2}\right) \ddot{\theta}+r^{2} \theta \dot{\theta}^{2}+g r \theta \cos \theta=0 .
$$

Here dot denotes differentiation with respect to time. 
By using the approximation $\cos \theta \approx 1-\frac{\theta^{2}}{2}+\ldots$, and substituting into Eq. (1), we have:

$$
\left(\frac{1}{12} l^{2}+r^{2} \theta^{2}\right) \ddot{\theta}+r^{2} \theta \dot{\theta}^{2}+g r \theta-\frac{g r}{2} \theta^{3}=0 .
$$

And initial conditions:

$$
\theta(0)=A \text { and } \frac{d \theta}{d t}(0)=0
$$

According to He's Frequency-Amplitude Formulation [19,20], we choose two trial functions $\theta_{1}(t)=A \cos t$ and $\theta_{2}(t)=A \cos \omega t$, which are, respectively, the solutions of the following linear equations:

$$
\begin{aligned}
& \ddot{\theta}+\omega_{1}^{2} \theta=0, \quad \omega_{1}^{2}=1 \\
& \ddot{\theta}+\omega_{2}^{2} \theta=0, \omega_{2}^{2}=\omega^{2} .
\end{aligned}
$$

The residuals are:

$$
\begin{aligned}
& R_{1}(t)=\left(-A l^{2} / 12+r^{2} A^{3}+g r A\right) \cos t-\left(2 r^{2} A^{3}+g r A^{3} / 2\right) \cos ^{3} t \\
& R_{2}(t)=\left(-l^{2} \omega^{2} A / 12+r^{2} \omega^{2} A^{3}+g r A\right) \cos \omega t-\left(2 r^{2} \omega^{2} A^{3}+g r A^{3} / 2\right) \cos ^{3} \omega t .
\end{aligned}
$$

We introduce two new residual variables $\tilde{R}_{1}$ and $\tilde{R}_{2}$ as

$$
\tilde{R}_{1}=\frac{4}{T_{1}} \int_{0}^{T_{1} / 4} R_{1}(t) \cos \left(\frac{2 \pi}{T_{1}} t\right) d t
$$

And

$$
\tilde{R}_{2}=\frac{4}{T_{2}} \int_{0}^{T_{2} / 4} R_{2}(t) \cos \left(\frac{2 \pi}{T_{2}} t\right) d t .
$$

We can approximately determine $\omega^{2}$ in the form

$$
\omega^{2}=\frac{\omega_{1}^{2} \tilde{R}_{2}-\omega_{2}^{2} \tilde{R}_{1}}{\tilde{R}_{2}-\tilde{R}_{1}}
$$

By a simple calculation, Eq. (2) can be expressed as:

$$
\tilde{R}_{1}=\frac{4 g r A-A l^{2} / 3-2 r^{2} A^{3}-1.5 g r A^{3}}{8}
$$

And

$$
\tilde{R}_{2}=\frac{-\left(2 r^{2} A^{3}+l^{2} A / 3\right) \omega^{2}-1.5 g r A^{3}+4 g r A}{8}
$$

Substituting Eqs (4), (5), (11) and (12) into Eq. (10) leads to:

$$
\omega^{2}=\frac{\left(1.5 g r A^{3}-4 g r A\right) \omega^{2}+4 g r A-1.5 g r A^{3}}{-\left(2 r^{2} A^{3}+l^{2} A / 3\right) \omega^{2}+2 r^{2} A^{3}+l^{2} A / 3},
$$

Its approximate frequency reads:

$$
\omega=\sqrt{\frac{-b \pm \sqrt{b^{2}-4 a c}}{2 a}},
$$

Where $a, b$ and $c$ are as follows:

$$
a=2 r^{2} A^{3}+l^{2} A / 3, \quad b=1.5 g r A^{3}-2 r^{2} A^{3}-4 g r A-l^{2} A / 3, \quad c=4 g r A-1.5 g r A^{3} .
$$

The periodic solution is as follows:

$$
\theta(t)=A \cos \omega t,
$$


Table 1

Values of variables in Eq. (1), for two modes

\begin{tabular}{cccc}
\hline Mode & $L$ & $r$ & $g$ \\
\hline 1 & 12 & 3 & 9.81 \\
2 & 12 & 1 & 9.81 \\
\hline
\end{tabular}

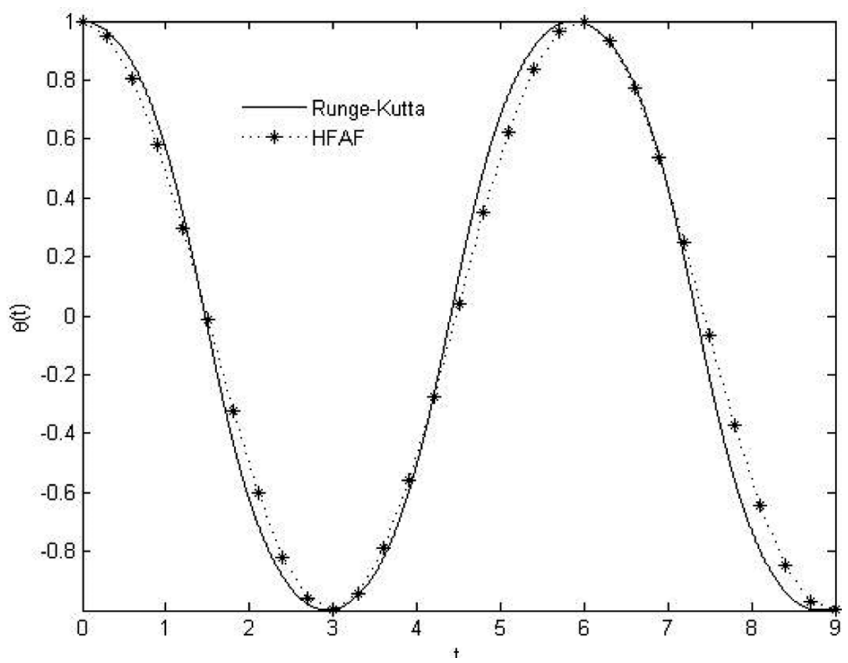

Fig. 2. The comparison between frequency-amplitude formulation with Runge-Kutta $4^{\text {th }}$ order for first mode, when $\mathrm{A}=1$.

Where $\omega$ is evaluated from Eq. (14).

According to Eq. (14), two various frequencies are obtained that one of them is the main frequency apparent through Eqs (4) and (5). The main frequency is distinguished via the coefficients of the proposed equation. We illustrate these statements for two modes.

The values of parameters $l, r$ and $g$ associated with the calculation modes are shown in Table 1 . We should use alternatively positive and negative symbols in Eq. (14), for the first and second modes. To show the remarkable accuracy of the obtained result, we compare the approximate periodic solutions with Runge-kutta $4^{\text {th }}$ order in Figs 2 and 3 .

Figures 4 and 5 also present the phase-plan diagrams of the analytical approach (HFAF) in comparison with Runge-Kutta $4^{\text {th }}$ order.

\subsection{Case 2}

Free vibrations of an autonomous conservative oscillator with inertia and static type fifth-order non-linearity (Fig. 6), is expressed by [35,36];

$$
\ddot{u}+\lambda u+\varepsilon_{1} u^{2} \ddot{u}+\varepsilon_{1} u \dot{u}^{2}+\varepsilon_{2} u^{4} \ddot{u}+2 \varepsilon_{2} u^{3} \dot{u}^{2}+\varepsilon_{3} u^{3}+\varepsilon_{4} u^{5}=0 .
$$

With initial conditions:

$$
u(0)=A \text { and } \dot{u}(0)=0
$$

$\lambda$ is an integer which may take values of $\lambda=1,0$ or -1 , and $\varepsilon_{1}, \varepsilon_{2}, \varepsilon_{3}$ and $\varepsilon_{4}$ are positive parameters which are shown in Table 2.

This oscillation system is modeled as a restrained uniform beam carrying an intermediate lumped mass along its span. The effect of rotary inertia and shearing deformation is neglected, because the beam thickness is assumed to be small compared to the length.

According to He's Frequency-Amplitude Formulation [19,20], we choose two trial functions $u_{1}(t)=A \cos t$ and $u_{2}(t)=A \cos \omega t$. 
Table 2

Values of dimensionless parameters $\varepsilon_{i}$ in Eq. (17), for two modes

\begin{tabular}{ccccc}
\hline Mode & $\varepsilon_{1}$ & $\varepsilon_{2}$ & $\varepsilon_{3}$ & $\varepsilon_{4}$ \\
\hline 1 & 0.326845 & 0.129579 & 0.232598 & 0.087584 \\
2 & 1.642033 & 0.913055 & 0.313561 & 0.204297 \\
\hline
\end{tabular}

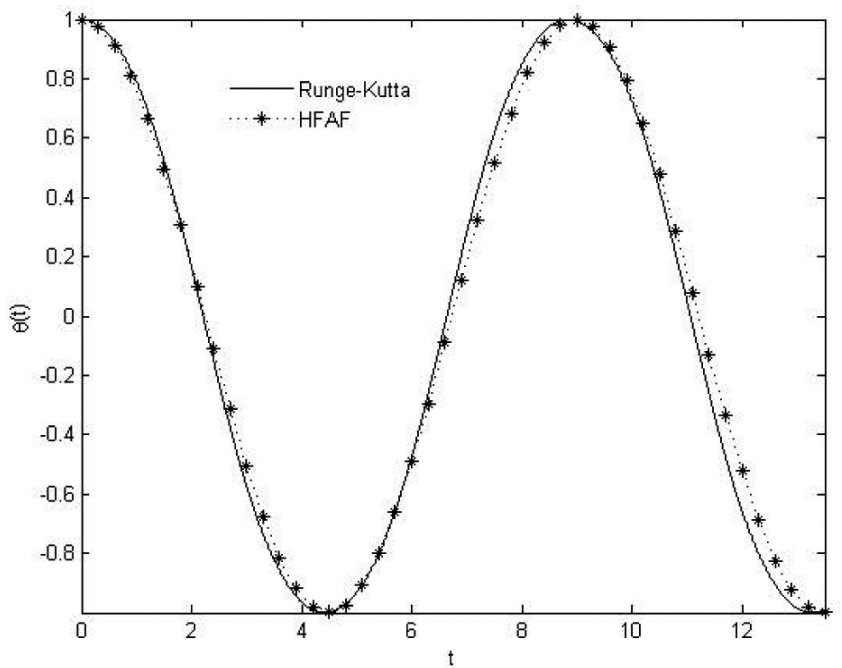

Fig. 3. The comparison between frequency-amplitude formulation with Runge-Kutta $4^{\text {th }}$ order for second mode, when A $=1$.

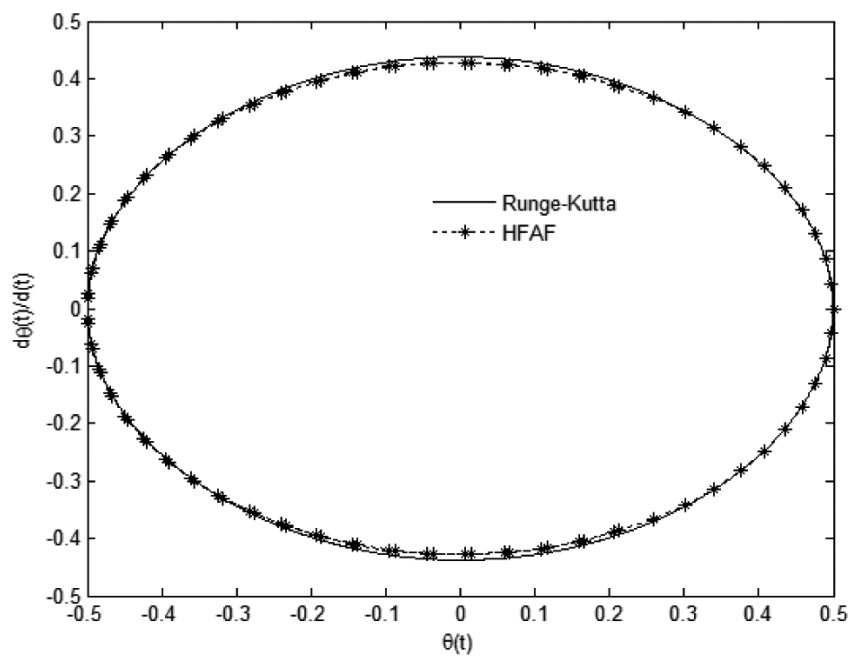

Fig. 4. Phase-plan diagram for first mode, when $\mathrm{A}=0.5$.

The residuals are:

$$
\begin{aligned}
R_{1}(t) & =\left(-A+\lambda A+\varepsilon_{1} A^{3}\right) \cos t-\left(2 \varepsilon_{1} A^{3}-\varepsilon_{3} A^{3}-2 \varepsilon_{2} A^{5}\right) \cos ^{3} t-\left(3 \varepsilon_{2} A^{5}-\varepsilon_{4} A^{5}\right) \cos ^{5} t \\
R_{2}(t) & =\left(-A \omega^{2}+\lambda A+\varepsilon_{1} A^{3} \omega^{2}\right) \cos \omega t-\left(2 \varepsilon_{1} A^{3} \omega^{2}-2 \varepsilon_{2} A^{5} \omega^{2}-\varepsilon_{3} A^{3}\right) \cos ^{3} \omega t- \\
& \left(3 \varepsilon_{2} A^{5} \omega^{2}-\varepsilon_{4} A^{5}\right) \cos ^{5} \omega t .
\end{aligned}
$$

Thus, for Eq. (17), we obtain:

$$
\tilde{R}_{1}=\frac{-8 A+8 \lambda A-4 \varepsilon_{1} A^{3}-3 \varepsilon_{2} A^{5}+6 \varepsilon_{3} A^{3}+5 \varepsilon_{4} A^{5}}{16}
$$




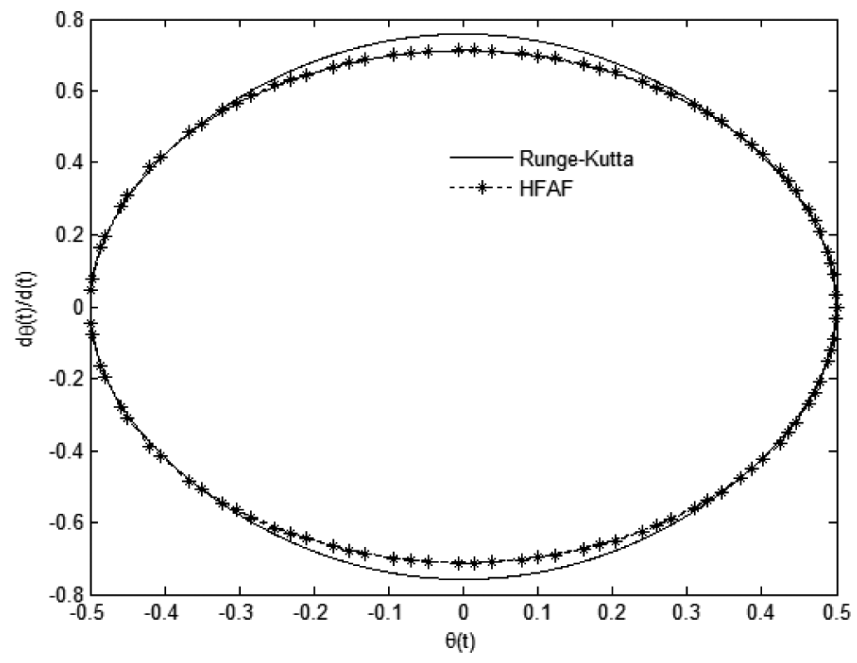

Fig. 5. Phase-plan diagram for second mode, when $\mathrm{A}=0.5$.

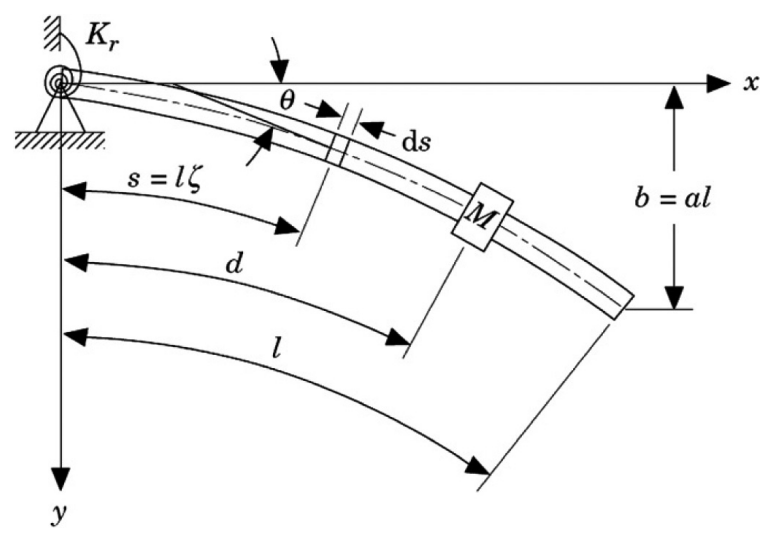

Fig. 6. A sketh of the beam system under study.

And,

$$
\tilde{R}_{2}=\frac{-8 A \omega^{2}+8 \lambda A-4 \varepsilon_{1} A^{3} \omega^{2}-3 \varepsilon_{2} A^{5} \omega^{2}+6 \varepsilon_{3} A^{3}+5 \varepsilon_{4} A^{5}}{16}
$$

According to Eq. (10), $\omega^{2}$ can be written as:

$$
\omega^{2}=\frac{-\left(8 \lambda A+6 \varepsilon_{3} A^{3}+5 \varepsilon_{4} A^{5}\right) \omega^{2}+8 \lambda A+6 \varepsilon_{3} A^{3}+5 \varepsilon_{4} A^{5}}{-\left(8 A+4 \varepsilon_{1} A^{3}+3 \varepsilon_{2} A^{5}\right) \omega^{2}+8 A+4 \varepsilon_{1} A^{3}+3 \varepsilon_{2} A^{5}},
$$

Its approximate frequency reads:

$$
\omega=\sqrt{\frac{-b \pm \sqrt{b^{2}-4 a c}}{2 a}}
$$

Where $a, b$ and $c$ are as follows:

$$
\begin{aligned}
& a=8 A+4 \varepsilon_{1} A^{3}+3 \varepsilon_{2} A^{5}, \quad b=-\left(8 A+4 \varepsilon_{1} A^{3}+3 \varepsilon_{2} A^{5}+8 \lambda A+6 \varepsilon_{3} A^{3}+5 \varepsilon_{4} A^{5}\right), \\
& c=8 \lambda A+6 \varepsilon_{3} A^{5}+5 \varepsilon_{4} A^{5} .
\end{aligned}
$$

Therefore the periodic solution is as follows: 


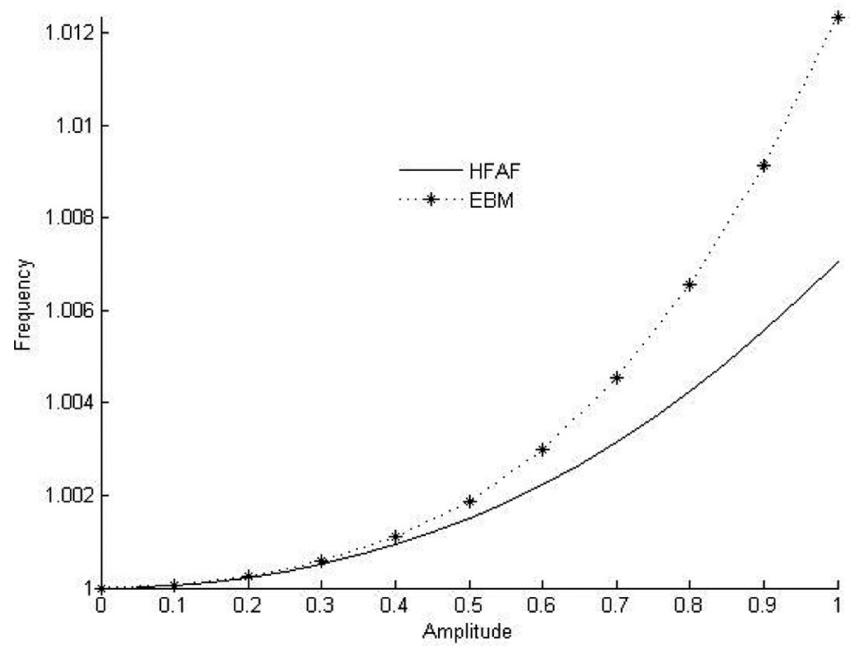

Fig. 7. The comparison between frequency-amplitude formulation and energy balance solution, when $\lambda=1$, for the first mode.

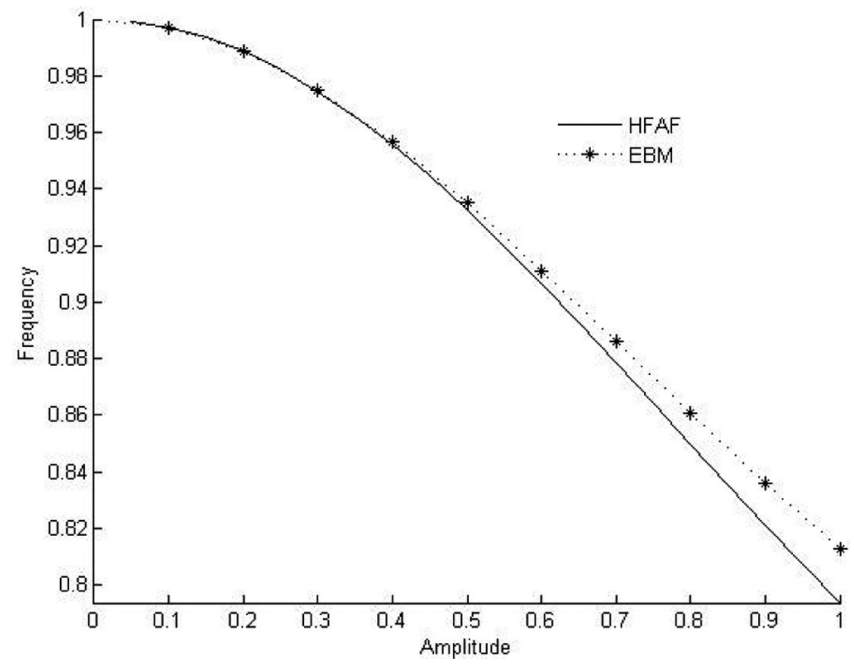

Fig. 8. The comparison between frequency-amplitude formulation with energy balance solution, when $\lambda=1$, for the second mode.

$$
u(t)=A \cos \omega t .
$$

Where $\omega$ is evaluated from Eq. (24).

As explained in former example, Eq. (24) leads to two separate frequencies for the vibration of Eq. (17). In this example, the main frequency is alternatively obtained by using positive and negative symbols in Eq. (24) for the first and second modes.

The energy balance frequency for the periodic solution to Eq. (17) is [37]:

$$
\omega_{e b m}=\frac{\sqrt{3}}{3} \sqrt{\frac{12 \lambda+9 \varepsilon_{3} A^{2}+7 \varepsilon_{4} A^{4}}{4+2 \varepsilon_{1} A^{2}+\varepsilon_{2} A^{4}}},
$$

The comparison between frequencies obtained by He's Frequency Amplitude Formulation and Energy Balance Method is shown in Figs 7, 8.

To show the remarkable accuracy of the obtained result, we compare the approximate periodic solutions with Runge-kutta $4^{\text {th }}$ order in Figs 9 and 10. 


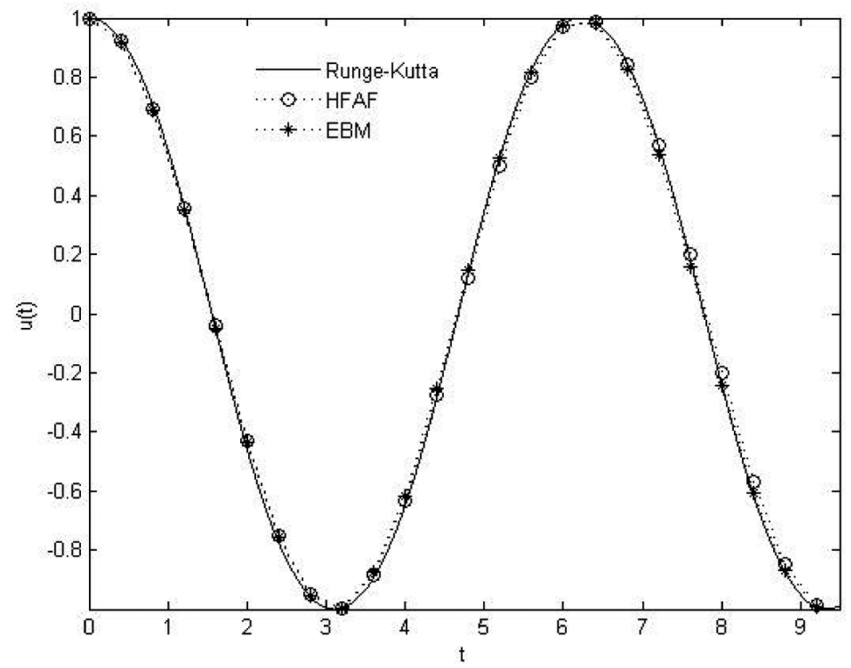

Fig. 9. The comparison between frequency-amplitude formulation with Runge-Kutta $4^{\text {th }}$ order and energy balance solutions when $\lambda=1$ and A $=1$, for the first mode.

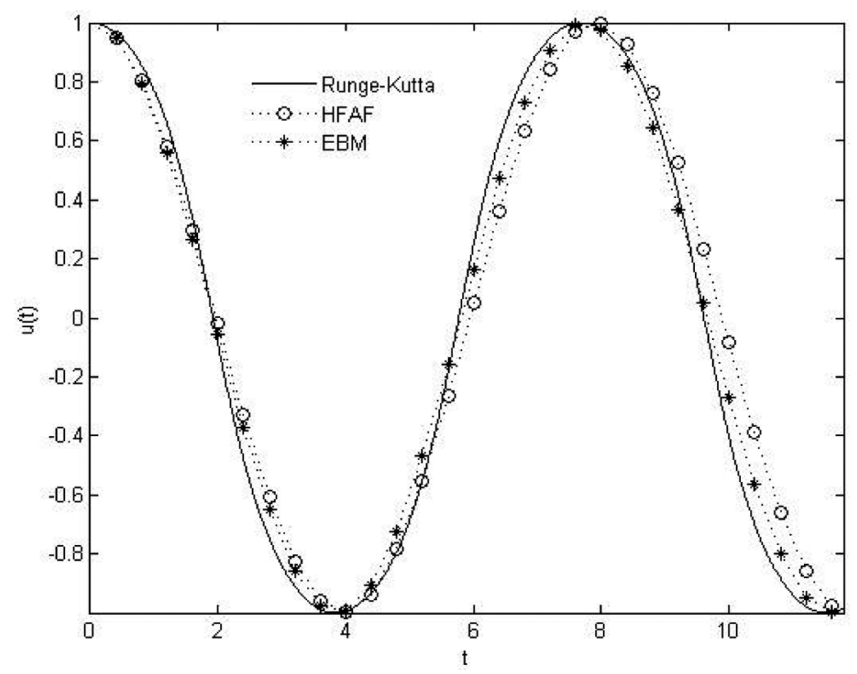

Fig. 10. The comparison between Frequency-amplitude formulation and Runge-Kutta $4^{\text {th }}$ order and energy balance solutions, when $\lambda=1$ and $\mathrm{A}=1$, for the second mode.

Figures 11 and 12 present the phase-plan diagrams of the analytical methods HFAF and EBM in comparison with Runge-Kutta $4^{\text {th }}$ order.

\section{Conclusions}

In this paper, we applied a new method, called He's frequency-amplitude formulation to two examples. In first example we considered a rigid rod rock on a circular surface. As it was shown earlier, the obtained equation has third order nonlinearity. For second example large amplitude vibration of a slender inextensible cantilever beam with an intermediate lumped mass is analyzed while it presents a strongly nonlinear conservative oscillator with both inertia and static type nonlinearity.

Both cases showed the effectiveness and precision of the presented approach. We also compared the results with Runge-Kutta $4^{t h}$ order to visualize their drastic approximate solutions. This method is simple and doesn't need to 


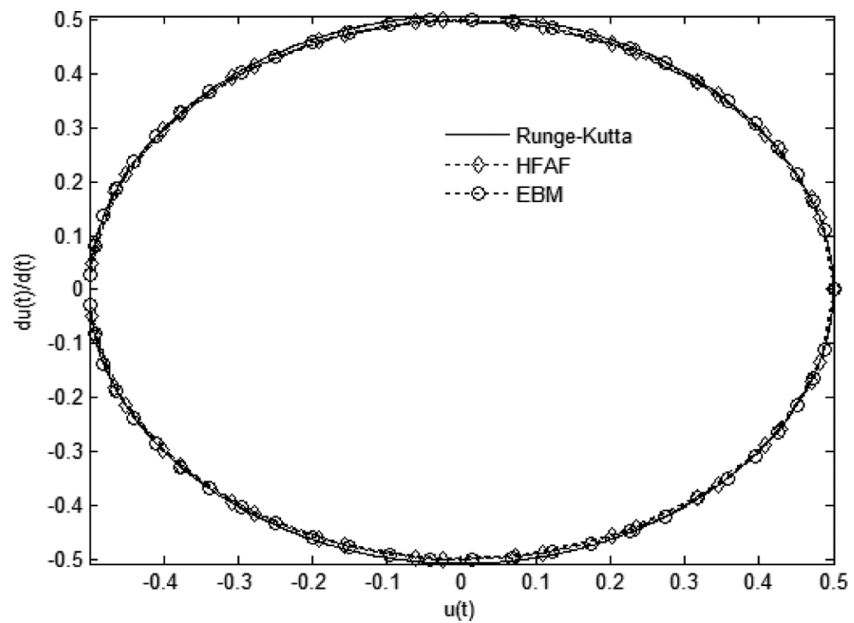

Fig. 11. Phase-plan diagram for first mode, when $\mathrm{A}=0.5$.

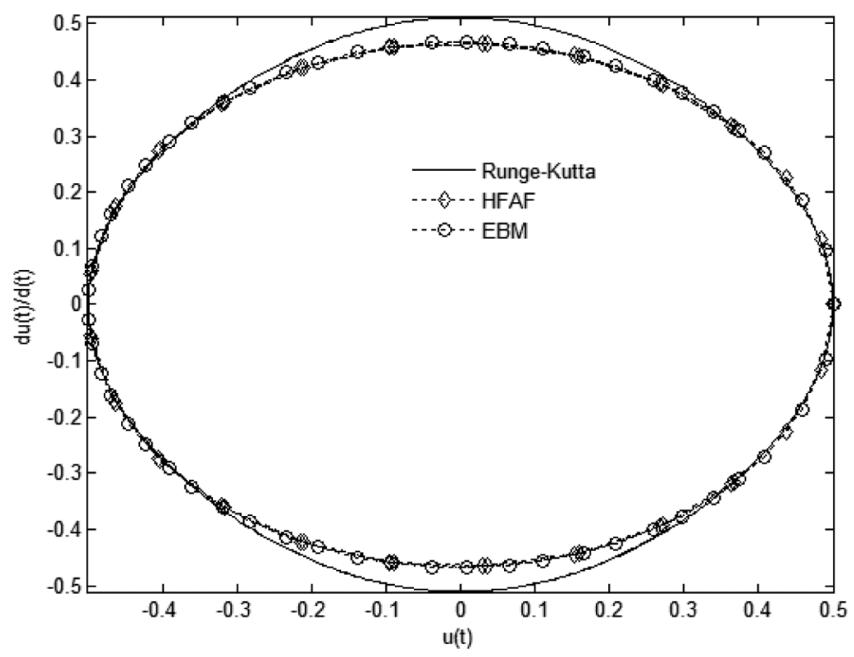

Fig. 12. Phase-plan diagram for second mode, when $\mathrm{A}=0.5$.

programming but it is important to choose the correct frequency for solving some complicated problems. It can be approved that HFAF is powerful and efficient technique in finding analytical solutions for a wide classes of nonlinear oscillator.

\section{References}

[1] A. Fidlin, Nonlinear Oscillations in Mechanical Engineering, Springer-Verlag, Berlin Heidelberg, 2006.

[2] R.E. Mickens, Oscillations in planar Dynamics Systems, World Scientific, Singapore, 1996.

[3] J.H. He, Non-Perturbative Methods for Strongly Nonlinear Problems, Disseration.de-Verlag in Internet GmbH, Berlin, 2006.

[4] A. Barari, M. Omidvar, D.D. Ganji and A. Tahmasebi Poor, An Approximate solution for boundary value problems in structural engineering and fluid mechanics, Journal of Mathematical Problems in Engineering (2008), Article ID 394103, 1-13.

[5] Sh. Momani and S. Abuasad, Application of He's variational iteration method to Helmholts equation, Chaos Solitons \& Fractals 27 (2006), $1119-1123$.

[6] A. Fereidoon, M. Ghadimi, H.D. Kaliji, M. Eftari and S. Alinia, Variational Iteration Method for Nonlinear Vibration of Systems with Linear and Nonlinear Stiffness, International Journal of Research and Review in Applied Sciences 5(3) (2010), 260-263.

[7] A. Barari, M. Omidvar, Abdoul R. Ghotbi and D.D. Ganji, Application of homotopy perturbation method and variational iteration method to nonlinear oscillator differential equations, Acta Applicandae Mathematicae 104 (2008), 161-171. 
[8] M.G. Sfahani, S.S. Ganji, A. Barari, H. Mirgolbabaei and G. Domairry, Analytical Solutions to Nonlinear Conservative Oscillator with Fifth-Order Non-linearity, Earthquake Engineering and Engineering Vibration 9(3) (2010), 367-374.

[9] M. Bayat, M. Shahidi, A. Barari and G. Domairry, The approximate analysis of nonlinear behavior of structure under harmonic loading, International Journal of the Physical Sciences 5(7) (2010), 1074-1080.

[10] M. Bayat, M. Shahidi, A. Barari and G. Domairry, Analytical evaluation of the nonlinear vibration of coupled oscillator systems, Zeitschrift für Naturforschung A 66a(1) (2011), 1-16.

[11] M. Momeni, N. Jamshidi, A. Barari and D.D. Ganji, Application of He's Energy Balance Method to Duffing Harmonic Oscillators, International Journal of Computer Mathematics 88(1) (2010), 135-144.

[12] S.S. Ganji, D.D. Ganji, Z.Z. Ganji and S. Karimpour, Periodic solution for strongly nonlinear vibration system by He's energy balance method, Acta Applicandae Mathematicae (2008), doi:10.1007/s10440-008-9283-6.

[13] J.H. He, Preliminary report on the energy balance for nonlinear oscillations, Mechanics Research Communications 29(2-3) (2002), $107-111$.

[14] H. Askari, M. Kalami Yazdi and Z. Saadatnia, Frequency analysis of nonlinear oscillators with rational restoring force via He's Energy Balance Method and He's Variational Approach, Nonlinear Sci Lett A 1 (2010), 425-430.

[15] L.B. Ibsen, A. Barari and A. Kimiaeifar, Analysis of highly nonlinear oscillation systems using He's max-min method and comparison with homotopy analysis and energy balance methods, Sadhana 35 (2010), 1-16.

[16] H. Babazadeh, G. Domairry, A. Barari, R. Azami and A.G. Davodi, Numerical analysis of strongly nonlinear oscillation systems using He's max-min method, Frontiers of Mechanical Engineering in China (2011), DOI 10.1007/s11465-009-0033-x, 2010.

[17] J. Biazar and F. Mohammadi, Multi-step Differential Transform Method for nonlinear oscillators, Nonlinear Sci Lett A 1 (2010), $391-397$.

[18] S.S. Ganji, A. Barari, L.B. Ibsen and G. Domairry, Differential Transform Method for mathematical modeling of Jamming transition problem in traffic congestion flow, Central European Journal of Operations Research (2011), DOI: 10.1007/s10100-010-0154-7.

[19] J.H. He, An improved amplitude-frequency formulation for nonlinear oscillators, International Journal of Nonlinear Sciences and Numerical Simulation 9(2) (2008), 211-212.

[20] J.H. He, Some asymptotic methods for strongly nonlinear equations, International Journal of Modern Physic B 20 (2006), $1141-1199$.

[21] M.T. Darvishi, S. Kheybari and A. Yildirim, Application of He's Parameter-expansion Method to a system of two van der Pol oscillators coupled via a Bath, Nonlinear Sci Lett A 1 (2010), 399-405.

[22] F. Boumediene, A. Miloudi, J.M. Cadou, L. Duigou and E.H. Boutyour, Nonlinear forced vibration of damped plates by an asymptotic numerical method, Computers and Structures 87 (2009), 1508-1515.

[23] M. Bayat, A. Barari and M. Shahidi, Dynamic Response of Axially Loaded Euler-Bernoulli Beams, Mechanika, 2011, in press.

[24] M.I. Qaisi, Application of the harmonic balance principle to the nonlinear free vibration of beams, Applied Acoustics 40(2) (1993), $141-151$.

[25] S.S. Ganji, A. Barari and D.D. Ganji, Approximate analyses of two mass-spring systems and buckling of a column, Computers \& Mathematics with Applications 61(4) (2011), 1088-1095.

[26] A. Kimiaeifar, E. Lund, O.T. Thomsen and A. Barari, On Approximate analytical solutions of nonlinear vibrations of inextensible beams using Parameter-Expansion Method, International Journal of Nonlinear Sciences and Numerical Simulation 11(9) (2010), 743-753.

[27] N. Jacques, E.M. Daya and M. Potier-Ferry, Nonlinear vibration of viscoelastic sandwich beams by the harmonic balance and finite element methods, Journal of Sound and Vibration 329 (2010), 4251-4265.

[28] M. Baghani, R.A. Jafari-Talookolaei and H. Salarieh, Large amplitudes free vibrations and post-buckling analysis of unsymmetrically laminated composite beams on nonlinear elastic foundation, Applied Mathematical Modelling 35 (2011), $130-138$.

[29] M.G. Sfahani, A. Barari, M. Omidvar, S.S. Ganji and G. Domairry, Dynamic response of inextensible beams by improved energy balance method, Proceedings of the Institution of Mechanical Engineers, Part K: Journal of Multi-body Dynamics 225(1) (2011), 66-73.

[30] M.A. Noor, K.I. Noor and S.T. Mohyud-Din, Modified variational iteration technique for solving singular fourth-order parabolic partial differential equations, Nonlinear Analysis 71 (2009), 630-640.

[31] Abd Elhalim Ebaid. Analytical periodic solution to a generalized nonlinear oscillator: Application of He's frequency-amplitude formulation, Mechanics Research Communications 37 (2010), 111-112.

[32] Jie Fan, He's frequency-amplitude formulation for the Duffing harmonic Oscillator, Computers and Mathematics with Applications 58 (2009), 2473-2476.

[33] Hui-Li Zhang, Application of He's amplitude-frequency formulation to a nonlinear oscillator with discontinuity, Computers and Mathematics with Applications 58 (2009), 2197-2198.

[34] E.W. Gaylord, Natural frequencies of two nonlinear systems compared with the pendulum, Journal of Applied Mechanics 26 (1959), 145146, 85.

[35] Shih-Shin Chen and Cha'o-Kuang Chen, Application of the differential transformation method to the free vibrations of strongly non-linear oscillators, Nonlinear Analysis: Real World Applications 10 (2009), 881-888.

[36] M.N. Hamden and N.H. Shabaneh, On the large amplitude free vibrations of a restrained uniform beam carrying an intermediate lumped mass, Journal of Sound and Vibration 199 (1997), 711-736.

[37] I. Mehdipour, D.D. Ganji and M. Mozaffari, Application of the energy balance method to nonlinear vibrating equations, Current Applied Physics 10 (2010), 104-112. 

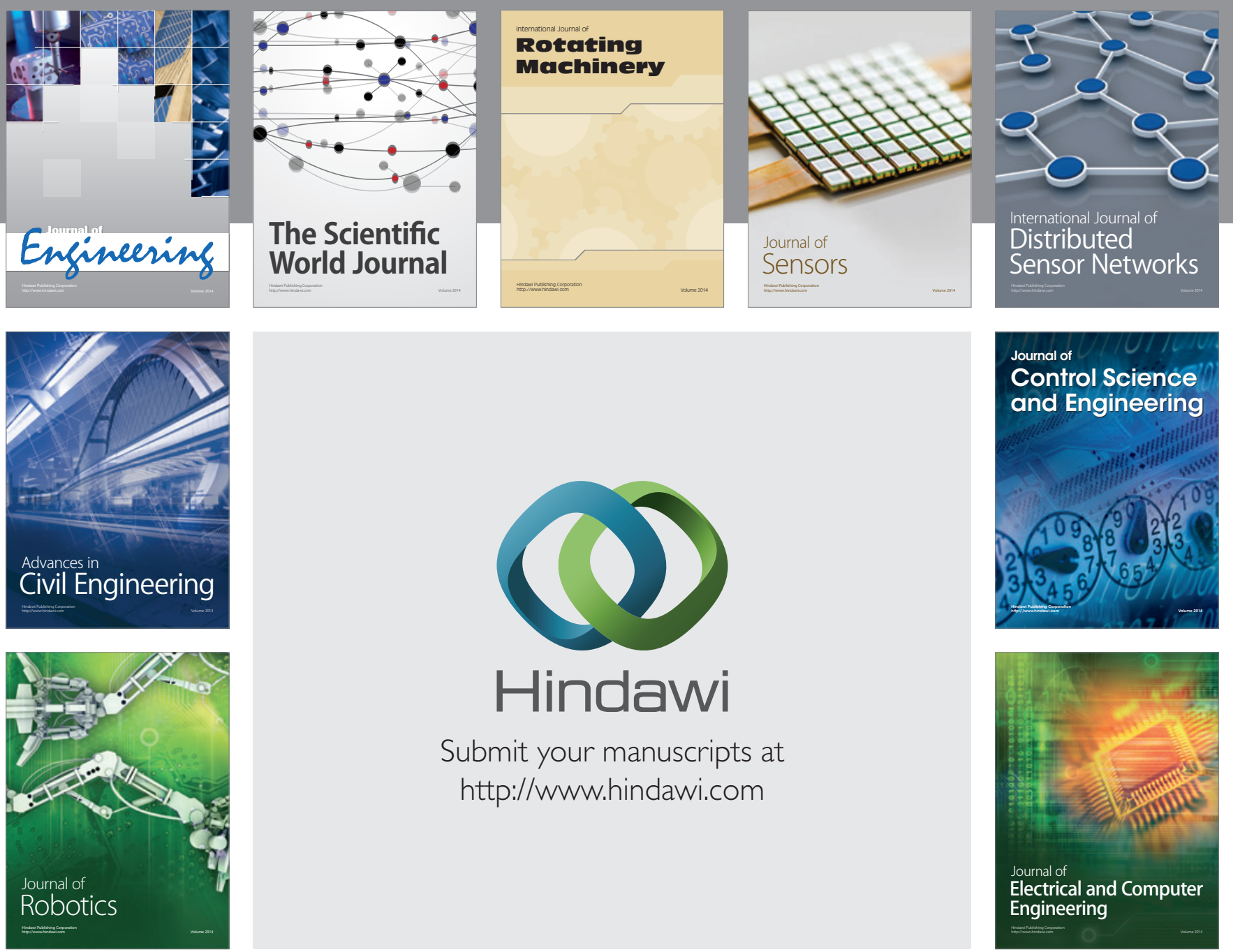

Submit your manuscripts at

http://www.hindawi.com
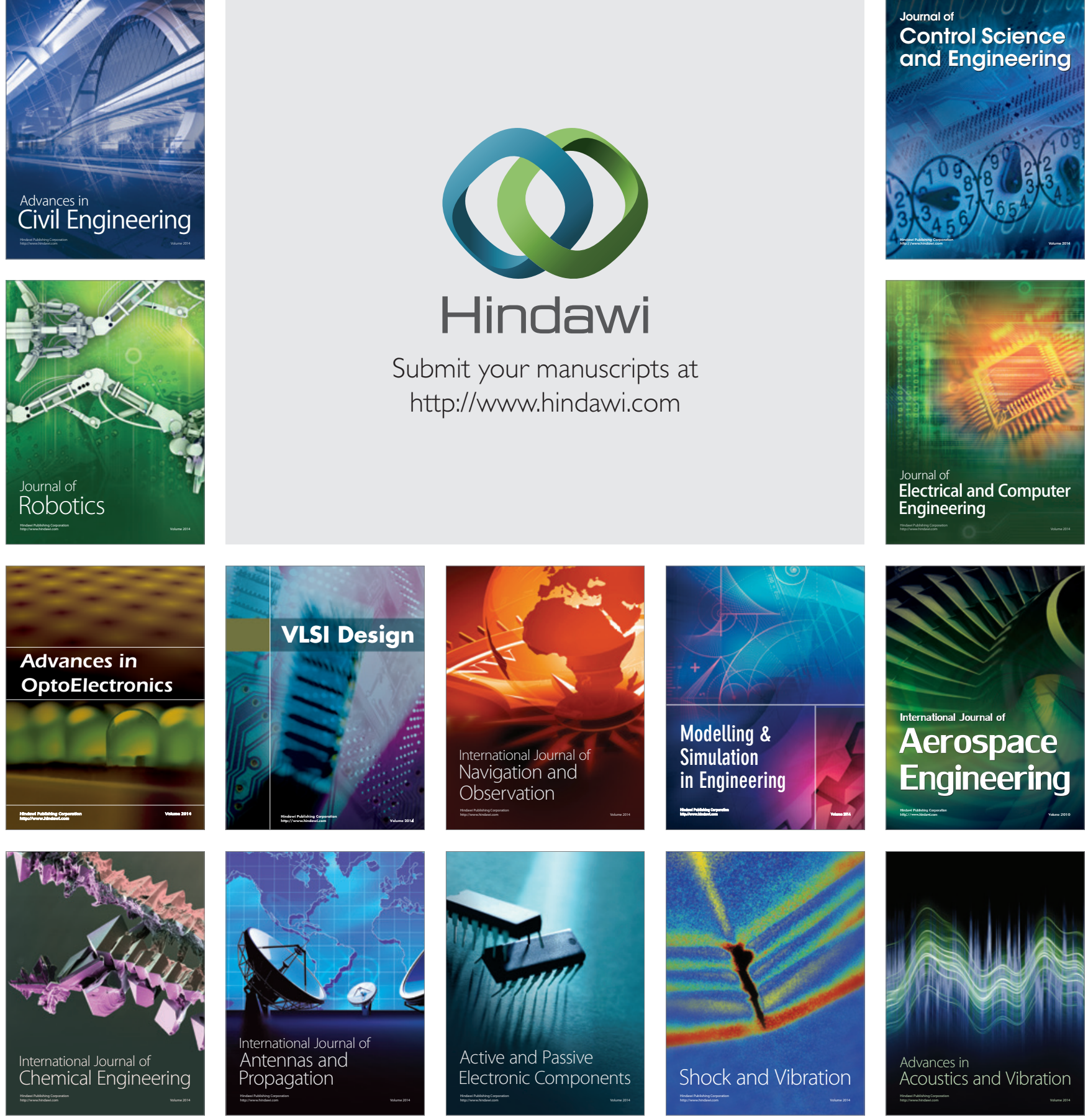